\title{
Living with schizophrenic disabilities
}

\author{
MOUNIR Y. EKDAWI \\ F.R.C.Psych.
}

Netherne Hospital, Coulsdon, Surrey

\section{The concepts of disability in schizophrenia}

A variety of medical disorders result in clusters of persistent symptoms and related problems, known as disabilities. Some understanding of the nature of consequent handicaps, and the factors which influence their magnitude, is the sine qua non of coping with these disabling conditions. This understanding is not required on the part of the disabled person alone; disabilities often have serious implications which affect the lives of the family and other members of the community, whose appreciation of the disabled person's problems could be the starting point in changes of attitudes, provisions and legislation, so that disabilities can be lived with.

Several long-term follow up studies have shown a demonstrable, progressive improvement in the prognosis of schizophrenia during the last 50 years (Mayer-Gross, Slater and Roth, 1977; Bleuler, 1974; Ciompi, 1980); however, a large proportion of sufferers from the disorder persistently retain chronic symptoms and some are liable to recurrent exacerbations of acute symptoms. The view that this group of people are disabled in the same way as sufferers from other chronic medical conditions was crystallized by Wing (1961), who also introduced a reliable subclassification of the schizophrenic clinical impairments. This concept was widened to include, among the disabilities, the cumulative personal reactions to impairments and the social disadvantages which commonly affect disabled people. A summary of the various types of psychiatric disabilities, which is particularly of relevance to chronic schizophrenia, was given in the report of a Royal College of Psychiatrists' working party on rehabilitation (1980). There are many advantages in adopting this model when considering the problems of disabled people; it facilitates and sharpens the assessment of handicaps (Hall, 1981) and it serves as a useful guide in planning rehabilitation programmes and provision of services (Ekdawi, 1972). For the disabled person and his relatives, it provides a basis for understanding the limitations imposed by the chronic disorder, as well as an appreciation of their nature, so that the effect of social withdrawal, for instance, may not be construed as laziness; putting the facts of chronicity in a medical context is also helpful in reducing stigma, with its additional handicapping effects.

Two recognizable, though not unrelated, sets of clinical impairments have been described in chronic schizophrenia; the presence of formal thought disorder, in combination with delusions and hallucinations, usually with accompanying behaviour abnormalities (positive symptoms) constitute one chronic syndrome. Bleuler's fundamental symptoms (Bleuler, 1950) are the group of clinical impairments which are known as negative symptoms; they are fixed and immutable (Wing, 1975, 1978), and they tend to carry a poor prognosis (Mackay, 1, and Crow, 2,1980 ). This had led various authors to speculate from clinical observations (Morgan, 1979) and through a variety of assessments (Johnstone et al., 1981) that these symptoms are an integral part of a disease process, rather than purely the result of environmental influences. Nevertheless, these disabilities, whatever their origin, have been shown to be highly reactive to the environment, and to be susceptible to some change through certain methods of social management (Wing and Freudenberg, 1961; Ekdawi, 1966). In an important study spanning 8 years, Wing and Brown (1970) found marked differences in the degree of severity of chronic schizophrenic symptoms in the populations of three mental hospitals and these differences were significantly related to the prevalent social and environmental factors in the hospitals. A generalization of similar effects was found in a classical experiment where two groups of chronic schizophrenic patients attended an industrial rehabilitation unit; although all the patients remained handicapped, the likelihood of adverse reactions occurring outside the institutional setting was reduced by prior work and social preparation for rehabilitation in the hospital environment (Wing, Bennett and Denham, 1964). In schizophrenic patients living outside the hospital, the severity of disabilities was shown to be highly responsive to family atmosphere. A concise account of the seminal 
work spanning the last two decades of the Medical Research Council's Social Psychiatry Unit in the field of interaction between schizophrenic symptoms and the quality of the various environments was recently published in the British Medical Journal (Leading Article, 1980); it will be readily seen, however, that the problems of research which attempts to knit the multiple factors of impairment, social stimulation in a range of settings, life events and the role of medication into a coherent whole, cannot be overestimated.

Psychiatric symptoms which are not specific to chronic schizophrenia often occur in conjunction with more typical ones. Anhedonia, for example, is so ubiquitous that some authors have considered it to be related to the clinical disorder itself (Chapman and Raulin, 1976; Cook and Simukonda, 1981). Frank depressive symptoms also appear relatively frequently in the post-psychotic period of the illness (Siris, Harmon and Endicott, 1981) and neurotic-type symptoms are common in discharged chronic schizophrenic patients whose florid psychotic symptoms have been well controlled with neuroleptics (Korer, Freeman and Cheadle, 1978; Cheadle, Freeman and Korer, 1978). Such symptoms may, in fact, be persistent and extremely disabling, causing malfunction in the community; in a six years' follow-up study, the appearance or recrudescence of these symptoms were associated with hospital re-admission of some rehabilitated patients (Acharya et al., 1982). In particular, the high morbidity in schizophrenic patients, due to anxiety as a reaction to problems of living was high-lighted by Mendel (1977) in observations accumulated over 20 years.

The available evidence, therefore, suggests that the variable course of chronic schizophrenia is due to a complex interaction between clinical and social factors, which may lead to an aftermath of suffering and poor adaptation. To disregard the realities of disability or to dismiss them as mythical (Szasz, 1976) can only retard our comprehension of these complex issues and may further compound the stigma of the sufferers. It is surely more rational to view the problems of chronic schizophrenia, regardless of any theoretical orientation, as disabilities which could limit or disrupt social integration (Mendel, 1977). An acceptance of this view would then serve as a basis for action directed at minimizing these problems so that they can be liveable with.

\section{The experience of disability}

\section{As felt by the patient}

The experience of disabling conditions and their consequences is a shared one; apart from the disabled person, it involves their relatives, the professional and voluntary workers and members of the wider community. Understanding the implications of living with disabilities is facilitated by contemplating some facets of the experience as perceived by those directly affected.

In classifying mental disorder, descriptive psychiatry has often tacitly or explicitly employed the concept that psychotic experience is difficult to understand or empathize with (Fish, 1976). Karl Jaspers, for instance, believed that although the observation and accurate depiction of abnormal phenomena was essential this was naturally limited by the fact that patients were not physical objects (Jaspers, 1963). Even the patients' first-hand descriptions can only be an approximation, having been shaped by personal factors and modified by the process of subjecting highly unusual experience to the constraints of common language. Nevertheless, the view from within can shed more light on the experience of schizophrenia than can be achieved by 'objective' observation. Interest in the inner world of schizophrenic patients was deepened by the work of psychoanalysts, as exemplified by the studies of Schreber's memoirs (Schreber, 1955) and of Perceval's narrative (Perceval, 1961) and by material collected by Fromm-Reichman (1939) in the course of psychoanalytical treatment. The patients' autobiographical accounts are usually vividly readable, free from jargon and rich in illuminating detail (Anonymous, 1925; Sechehaye, 1951; Kaplan, 1964). They have also added to our understanding of the perceptual and cognitive disturbances which accompany the experience. Having reveiwed over 50 autobiographical books and articles by schizophrenic and other mentally ill patients, Freedman (1974) argued that the systematic exploration of patients' subjective experiences would sharpen the diagnostic process and could point to directions for research. In addition, patients' accounts often depict how it feels to be on the receiving end of treatment in certain environmental settings (Anonymous, 1931; Ward, 1946); they also clarify certain contentious political issues such as the consequences of labelling (Scheff, 1967) by describing their implications for the person concerned (Mosher, 1978). For the purposes of this paper, the most relevant material comes from a series of moving essays by 7 intelligent and literate patients (Anonymous, 1980). Not only do the authors portray their experience of acute symptoms, but they also describe the impact of disabilities on their lives in a variety of contexts. Even more relevantly, the authors highlight aspects of the painful path towards insight and eventual adjustment. Living with schizophrenic disabilities is seen as the attainment of a fairly dispassionate view of psychotic experiences and some knowledge of factors which trigger off or exacerbate symptoms, as well as ways of coping with or avoiding 
them. Such knowledge may also serve as a guide to sensible planning of services for disabled people, as illustrated by a recent study in which consumer opinion, on the rehabilitation provisions in a health district, was canvassed (Collis and Ekdawi, 1981).

\section{The effect on the relatives}

There is a wealth of information in the literature on the possible noxious effects of certain family environments on schizophrenic disabilities. Many studies have, for instance, focused on disordered family communications in relation to the genesis of schizophrenic symptoms (Wynne and Singer, 1963; Hirsch and Leff, 1975; Rutter, 1978) as well as on the relevance of the family's predominant emotional atmosphere to relapse (Leading Article, 1980). In 1963, Freeman and Simmons found that discharged schizophrenic patients who had low levels of social performance tended to be concentrated in parental homes, and they opined that over-tolerant milieux could discourage higher levels of function. The type of living accommodation was also shown to bear a very significant relationship to employment status in a 10-year follow up study of the results of the Netherne Resettlement Unit (Ekdawi, 1972); the greatest proportion of unemployed disabled patients was found to be in those living with their parents. A similar picture was later seen, in the same health district, in a 6 years study of a day rehabilitation unit's results (Acharya et al., 1982). It would probably be inaccurate, however, to conclude that parental homes must exercise a deleterious influence on social adjustment; assessments conducted during the latter study showed that many of the most socially disabled rehabilitees continued to live with their parents, who were more tolerant of abnormal behaviour than could be expected in hostels or more independent provisions.

In a study of 125 families, Doll (1976) observed that some patients imposed heavy emotional and social strains on their families; the eventual reduced tolerance of some relatives led the patients to harbour bitter and antagonistic feelings and, thus, a vicious circle was created. Another detailed study of 80 relatives of patients living at home, eloquently conveyed the barely quantifiable chronic difficulties with which some families struggled (Wing and Greer, 1980). Most relatives gradually attempted to evolve a modus vivendi, a peaceful co-existence, in the face of a range of problems including social withdrawal, selfneglect, expressed odd ideas, socially embarrassing acts and threatening and violent behaviour. Concomitantly, many families suffered social humiliation and financial hardship. Furthermore, the often unpredictable course of the disorder and the fears of what the future might bring constitute, for many families, an ever-present threat (Ekdawi, 1981a). Thus the families seem to be as much victim of the disabilities as the patients.

\section{The reactions of others}

There are very few subjective statements by professional workers directly involved with the care of schizophrenic patients on how they perceive and experience the effects of disability, and such statements are usually incidental to accounts by patients (Sechehaye, 1951). Reactions of professionals can occasionally be intimated through the, perhaps not unbiased, complaints made to voluntary bodies, such as MIND or the National Schizophrenia Fellowship, by the disabled and their relatives. Typical comments from families were studied in a recent report (Wing and Greer, 1980) in which relatives have often felt that professional help fell short of their expectations. It was not unusual to find that speedy, appropriate action was not forthcoming in emergencies; insufficient professional explanation and counselling was common and many relatives were excluded from treatment, discharge and after-care plans and they were also left floundering without the necessary support when the patient lived at home. The dearth of provisions of day care and residential accommodation as well as the lack of practical and financial help from statutory sources were frequently mentioned. The relatives' all too common guilt feelings were sometimes amplified by implied professional judgement that they were to blame for the patients' disabilities. When a patient was particularly difficult, though not compulsorily detainable for treatment, families were liable to be left to their own devices; indeed, many such patients could be blacklisted by some services.

In general, schizophrenic patients are, if anything, less vociferous in expressing dissatisfaction with professional services. Some have, however, commented on the fact that their own personal handicaps and abilities were not taken into consideration; in the treatment context, individuality is often violated and the patient is processed in the system, with the unwarranted assumption that he represents just one case in a homogeneous group phenomenon, in a disorder whose hallmark is heterogeneity (Strauss and Carpenter, 1981). It is not therefore surprising that beating the system is occasionally seen by the patient as one of the elements of living with his disabilities.

Research has shown that in the hospital, attitudes of staff, particularly of nurses, exercise a powerful influence on the severity of disabilities (Wing and Brown, 1970); for this reason, further systematic understanding of professional workers' experiences would be of great interest. 
So far as the response of the wider community to schizophrenic disabilities is concerned, many negative attitudes can be deduced from the uneven and inadequate levels of provisions, including housing and employment opportunities. These attitudes are also reflected in the national welfare arrangements; a current case in point is the discrimination against chronic schizophrenic patients who are not exempt, in the same way as many other disabled people, from prescription charges.

\section{How to live with schizophrenic disabilities}

Available data suggests that despite improvements in the control of florid symptoms, disabled patients have not been enabled to attain adequate levels of community adjustment (Mosher and Menn, 1978). This is particularly disappointing since there is now a significant body of information on the spectrum of disabilities as well as on some of the factors which ameliorate or aggravate their effects. Wing (1978) has suggested a paradigm which develops adaptive skills and within which help can be offered; this includes enabling the patient to recognize and to avoid situations which exacerbate his symptoms, to share in making decisions on his treatment, to foster his coping abilities, and to fashion his ambitions in the light of his handicaps. It also includes assisting families to construct optimal environments and to develop techniques of coping with abnormal behaviour and fluctuating insight, to make good use of the services and to adjust their expectations at a realistic level. The task of professional workers includes learning (often from patients' and relatives' experiences) better methods of managing handicaps and facilitating the provision of services. The pursuit of realistic goals, in long-term management, has been emphasized by Freeman (1980). A refinement of assessment methods (Hall, 1981) and the planning of appropriate individual programmes of care and rehabilitation would naturally follow. Amongst the various rehabilitation techniques which enhance the process of adaptation to disability is on-going individual and group counselling (Ekdawi, 1981a) from which the patients, their families and those responsible for their care can derive much benefit.

Disabled people require a modicum of provisions to support and maintain them, to compensate for their handicaps and to enlarge their adaptive repertoire. Provisions must be adequate and sufficiently varied to cater for the gamut of needs. Community provisions must be superior, or, at least equivalent, to good hospital ones; however, there is evidence that some of the traditional, institutional patterns which propagated morbidity in mental hospital patients, have been recreated in some community facilities (Ekdawi, 1981b). Some disabled patients are, in fact, worse off after resettlement; they may suffer more disadvantage in a community setting which requires them to submit to an inflexible, authoritarian regime and which robs them from much of the autonomy they had acquired in hospital, for example, in looking after their own medication. They may also be so financially poorer as to be rendered destitute.

\section{Conclusion}

Wing (1977) has stated that the chief aim of the health services is to decrease or contain disease, disability or distress in the patient, his family and the community at large. To achieve this aim in the case of people disabled by schizophrenia a flexible system of care which takes account of the complex range of interactive variables is required, so that the sufferers can live with their disabilities without experiencing undue distress.

\section{Acknowledgments}

I am most grateful to Mrs V. Evans, Medical Secretary, and Mrs B. Saich, Hospital Librarian, for their assistance.

\section{References}

Acharya, S. Ekdawi, M.Y., Gallagher, L. \& Glaister, B. (1982) Day Hospital rehabilitation: a six-year study. Social Psychiatry, 17, 1.

ANONYMOUS (JSC) (1925) The mental patient as he feels himself. Journal of Mental Science, 71, 346.

ANONYMOUS (1931) The Asylum environment by an ex-patient. British Journal of Medical Psychology, 10, 344.

ANONYMOUS (Ed. WING, J.R.) (1980) Schizophrenia from within. In: Coping with Schizophrenia (Ed by Rollin, H.R.), The National Schizophrenia Fellowship, A. Deutsch, London.

Bleuler, E. (1950) Dementia Praecox, or the Group of Schizophrenias. International Universities Press, New York.

Bleuler, M. (1968) A 23-year longitudinal study of 208 schizophrenics. In: Transmission of Schizophrenia (Ed by Rosenthal, D.), Pergamon Press, Oxford.

BLEULER, M. (1974) The long-term course of the schizophrenia psychoses. Psychological Medicine, 4, 244.

ChaPMAN, J.P. \& RAULIN, M.L. (1976) Scales for physical and social anhedonia. Journal of Abnormal Psychology, 85, 374.

Cheadle, A.H., Freeman, H.L. \& Korer, J.R. (1978) Chronic schizophrenic patients in the community. British Journal of Psychiatry, 132, 221.

ClOMPI, L. (1980) The natural history of schizophrenia in the longterm. British Journal of Psychiatry, 136, 413.

Collis, M. \& EKDAWI, M.Y. (1981) Social adjustment in rehabilitation. Accepted for publication.

Cook, M. \& SimukondA, F. (1981) Anhedonia and schizophrenia. British Journal of Psychiatry, 139, 523.

DoLL, W. (1976) Family coping with the mentally ill: an unanticipated problem of deinstitutionalisation. Hospital and Community Psychiatry, 27, 183.

EKDAWI, M.Y. (1966) Changes in ward behaviour of severely disabled schizophrenic patients: a four years study. British Journal of Psychiatry, 112, 265.

EKDAWI, M.Y. (1972) The Netherne Resettlement Unit: results of ten years. British Journal of Psychiatry, 121, 417. 
EKDAWI, M.Y. (1981a) Counselling in rehabilitation. In: Handbook of Psychiatric Rehabilitation Practice (Ed by Wing, J.K. \& Morris, B.), Oxford University Press, Oxford.

EKDAWI, M.Y. (1981b) The role of day units in rehabilitation. I: Handbook of Psychiatric Rehabilitation Practice (Ed by Wing, J.K. \& Morris, B.) Oxford University Press, Oxford.

FISH, F.J. (1976) Schizophrenia. 2nd ed., Wright, Bristol.

FREEDMAN, B.J. (1974) The subjective experience of perceptual and cognitive disturbances in schizophrenia: a review of autobiographical accounts. Archives of General Psychiatry, 30, 333.

Freeman, H.E. \& Simmons, O. (1963) The Mental Patient Comes Home. John Wiley \& Sons, New York.

FREEMAN, H.L. (1980) Coping with schizophrenia. British Journal of Hospital Medicine, 23, 54.

Fromm-REICHMAN, F. (1939) Transference problems in schizophrenia. Psychoanalytic Quarterly, 8, 412.

GRIFFITHS, D. (1981) Psychological aspects of rehabilitation. In: Handbook of Psychiatric Rehabilitation Practice (Ed. by Wing, J.K. \& Morris, B.) Oxford University Press, Oxford.

HALL, N.J., (1981) Psychological assessment. In: Handbook of Psychiatric Rehabilitation Practice. (Ed by Wing, J.K. \& Morris, B.), Oxford University Press, Oxford.

HiRSH, S.R. \& LEFF, J.P. (1975) Abnormalities in Parents of Schizophrenics: a Review of the Literature and an Investigation of Communication Defects and Deviances. Maudsley Monograph No. 22, Oxford University Press, Oxford.

JASPERS, K. (1963) General Psychopathology (Trans. by Hoenig, J. \& Hamilton, M.W.), Manchester University Press, Manchester.

Johnstone, E.C., Cummingham OWens, D.G., Gold, A., Crow, T.J. \& MACMILLAN, J.F. (1981) Institutionalization and the defects of schizophrenia. British Journal of Psychiatry, 139, 195.

KAPLAN, B. (1964) The Inner World of Mental Illness: A series of first-person accounts of what it was like. Harper \& Row, New York.

Korer, J.R., Freeman, H.L. \& Cheadle, A.J. (1978) The social situation of schizophrenic patients living in the community. International Journal of Mental Health, 6, 45.

LEADING ARTICLE (1980) Social environment and relapse in schizophrenia. British Medical Journal, 2, 173.

MACKAY, A.V.P.(1) \& Crow, T.J.(2) (1980) Positive and negative schizophrenia symptoms and the role of dopamine. British Journal of Psychiatry, 137, 379.

MAYer-Gross, W., Slater, E. \& Roth, M. (1977) Schizophrenia, course and prognosis. In: Clinical Psychiatry, 3rd edn. Cassell, London.

MENDEL, W. (1977) Schizophrenia: The Experience and its Treatment, Jossey-Bass, San Francisco.

MOSHER, L.R. (1978) Can diagnosis be non-perjorative? In: The Nature of Schizophrenia (Ed by Wynne, L.C., Cromwell, R. \& Matthysse, S.), John Wiley \& Sons, New York.

MOSHER, L.R. \& MENN, A.Z. (1978) Enhancing psychological competence in schizophrenia: preliminary results of the Setoria
Project. In: Phenomenology and Treatment of Schizophrenia (Ed by Fann, W.E., Karacan, I., Pokorny, A.D. \& Williams, R.L.), Spectrum Publications, Jamaica, N.Y.

MORGAN, R. (1979) Conversations with chronic schizophrenic patients. British Journal of Psychiatry, 134, 187.

PerCeval, J. (1961) Perceval's Narrative (Ed by Bateson, G.) Stanford University Press, California. Hogarth Press, London.

Royal College of Psychiatrists (1980) Psychiatric Rehabilitation in the 1980s, London.

RUTTER, M. (1978) Communication deviance and diagnostic differences. In: The Nature of Schizophrenia (Ed by Wynne, L.C., Cromwell, R. \& Matthysse, S.), John Wiley \& Sons, New York.

SCHEFF, T.J. (1967) Being Mentally Ill. Weidenfeld \& Nicholson, London.

SCHREBER, D.P. (1955) Memoirs of My Nervous Illness. (Ed by Macalpine, I. \& Hunter, R.A.), William Dawson \& Sons, London.

SECHEHAYE, M. (1951) Autobiography of a Schizophrenic Girl. Grune \& Stratton Inc., New York.

SiRIS, G.S., HaRman, G.K. \& EndicotT, J. (1981) Postpsychotic depressive symptoms in hospitalised schizophrenic patients, Archives of General Psychiatry, 38, 1122.

STRAUSS, J.S. \& CARPENTER, W.T. JR. (1981) Schizophrenia. Plenum Medical Book Company, New York and London.

SZASZ, T.S. (1976) Schizophrenia: the sacred symbol of psychiatry. British Journal of Psychiatry, 129, 308.

WARD, M.J. (1946) The Snake Pit. Random House, New York.

WING, J.K. (1961) A simple and reliable subclassification of chronic schizophrenia. Journal of Mental Science, 107, 862.

WING, J.K. \& FREUDENBERG, R.K. (1961) The response of severely ill chronic schizophrenic patients to social stimulation. American Journal of Psychiatry, 118, 311.

Wing, J.K., BenNeTT, D.H. \& DenhaM, J. (1964) The Industrial Rehabilitation of Longstay Schizophrenic Patients. MRC Memo randum No. 42, H.M.S.O., London.

WING, J.K. \& BROWN, G.W. (1970) Institutionalism and Schizo phrenia. Cambridge University Press, London.

WING. J.K. (1975) Impairments in schizophrenia: a rational basis for social treatments. In: Life History Research in Psychopathology Vol. 4, (Ed by Wirt, R.D., Winokur, G. \& Roff, M.), University of Minnesota Press, Minneapolis.

WING, J.K. (1977) Schizophrenia and its management in the community. In: Psychiatric Medicine, (Ed by Usdin, G.), Brunner Mazel, New York.

WING, J.K. (1978) Clinical concepts of schizophrenia. In: Schizophrenia: Towards a New Synthesis, (Ed by Wing, J.K.), Academic Press, London.

WING, J. \& GREER, C. (1980)Schizophrenia at home. In: Coping with Schizophrenia, (Ed by Rollin, H.R.), The National Schizophrenia Fellowship, A, Deutsch, London.

WYNNE, L.C. \& SINGER, M.T. (1963) Thought disorder and family relations of schizophrenics, Archives of General Psychiatry, 9, 191 